\title{
Effect of Environmental Regulations on Foreign Direct Investment: Empirical Evidence From China
}

Dongbei Bai

Anhui University of Finance and Economics

Ling Cai Liu

Anhui University of Finance and Economics

Shah Fahad ( $\sim$ shah.fahad@xjtu.edu.cn)

Xi'an Jiaotong University https://orcid.org/0000-0002-7080-3031

\section{Zulfiqar Ali Baloch}

Northwest A\&amp;F University: Northwest Agriculture and Forestry University

\section{Research Article}

Keywords: Environmental Regulation, Foreign Direct Investment, Technological Innovation, Crowding-out Effect, Industry Sector

Posted Date: April 19th, 2021

DOI: https://doi.org/10.21203/rs.3.rs-394663/v1

License: (1) (1) This work is licensed under a Creative Commons Attribution 4.0 International License. Read Full License

Version of Record: A version of this preprint was published at Environmental Science and Pollution Research on August 20th, 2021. See the published version at https://doi.org/10.1007/s11356-021-152774. 
2

\title{
Effect of Environmental Regulations on Foreign Direct Investment: Empirical
} evidence from China

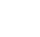

Dongbei Bai, Ling Cai Liu, Shah Fahad

${ }^{1}$ School of Economics, An Hui University of Finance and Economics, 233030 BengBu, China ${ }^{2}$ School of Management, Xi' an Jiaotong University, Xi'an 710049, China

${ }^{3}$ School of Economics and Managmeent, Northwest A\&F University, Yangling, Shaanxi China (1)

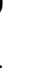

12

\author{
Dongbei Bai \\ School of Economics \\ An Hui University of Finance and Economics \\ 233030 BengBu, China \\ Email: 1878124720@qq.com
}

Ling Cai Liu

School of Economics

An Hui University of Finance and Economics

233030 BengBu, China

Email: fahad.hrm@outlook.com

Shah Fahad

School of Management

Xi'an Jiaotong University

Xi'an 710049, Shaanxi China

Email: shah.fahad@xjtu.edu.cn

ORCID: 0000-0002-7080-3031

Phone: 0086-18591927913

(Corresponding Author)

Zulfiqar Ali Baloch

School of Economics and Management

Northwest A\&F University

Yangling, Shaanxi China 


\section{Abstract:}

The industry selection effect arising from the impact of environmental regulation on Foreign Direct Investment (FDI) in China is heterogeneous. Based on an extension of the principal-agent Game Theory, this paper constructs a system of simultaneous equations to study the dynamic effect of environmental regulation on Chinese FDI in terms of industry selection decisions, by utilizing panel data from 2005 to 2014 in China. Results of this study show that environmental regulation promotes the technological innovation within the Chinese industry and attract greater foreign capital investment. While the influx of capital will furthermore boost technological progress, a benign interaction effect may be observed between technological innovation and foreign capital. The implementation of the new environmental policy will intensify game strategies between managers and enterprises. Enhanced co-ordination activity within industrial organizations will generate more effective organizational and technological innovation, thereby attracting a large flow of FDI, Phase analysis suggests that the policy of market borrowing technologies is more effective. In addition, industry sample results highlight a compensation effect of technological innovation in the raw materials and manufacturing industry, though environmental regulation of high-tech industries will generate an offset effect with respect to technological innovation. Industries that show the strongest technological and innovative prospects will prove the most attractive for foreign capital investment.

Keywords: Environmental Regulation; Foreign Direct Investment; Technological Innovation; Crowding-out Effect; Industry Sector

\section{Introduction}


Nearly 40 years after the adoption of the 'Reform and opening-up' policy, the Chinese economy has achieved rapid development. Foreign direct investment (FDI) has played a pivotal role in terms of growth within China's economy. China has attracted a large amount of FDI through the implementation of an active outward-oriented trade strategy. By the end of 2016, China country had utilized a cumulative sum of foreign capital totaling 126.01 billion USD. In addition, 27,900 cooperation projects were in operation and were distributed across $98 \%$ of all industrial sectors. A large amount of foreign capital has flowed into the industrial enterprise industry, promoting the growth of China's economy and leading to adjustments within industry structure, thereby generating improvements in industrial technology and enhanced scale structures. At the same time, the economy is rapidly developing, the environmental problems are getting worse, and the government has gradually reinforced environmental regulation standards in China. How the change of environmental regulation level influences the entry of FDI into Chinese enterprises and the heterogeneity of different industries? It is of great strategic significance to introduce foreign capital into China.

By opening up to the outside world, developing countries have adopted low environmental standards to attract foreign investment and develop their economies, largely in response to increasing globalization and a desire to achieve economic catch-up, which has aroused widespread concern among economists. Some researchers believe that to maintain market competitiveness, enterprises should actively avoid high standards of environmental control and select countries or regions with a relatively low level of environmental control (List et al., 2000; Xing and Kolstad, 2002), however, other scholars hold opposing views. While weak environmental regulations have led to the transfer of emission-intensive production activities from developed to developing countries, evaluation of the trade's income growth and technological effects highlights the way in which the cost of environmental regulation is relatively small in comparison with the production costs 
incurred by enterprises. It is difficult to propose a definitive conclusion regarding the impact of environmental regulation within international trade and investment (Antweiler et al., 2001). Although the Chinese government has complied with the comparative advantages of industrial structure and guided FDI in a standardized manner, the level of environmental pollution in China has continued to diminish with annual increasing in FDI inflows. It is true that during the 15-year-period from 2000 to 2014, foreign investment increased by $352.79 \%$, and the total exports for foreign-invested enterprises increased by $799.80 \%$. However, the study conducted in 2006 by the World Bank highlighted that 16 of the top 20 cities with the highest pollution levels were the Chinese cities, which is the world's largest emitter of sulfur dioxide. In addition, $58 \%$ of cities in China show an average atmospheric PM10 concentration that exceeds $100 \mu \mathrm{g} / \mathrm{m} 3$. According to the Environmental Performance Index published by Yale University and Columbia University, China ranked $109^{\text {th }}$ among the 180 countries in the 2016, the lowest rank among all countries and regions featured in the assessment (Shi et al.,2017). With the rapid import of FDI for economic development purposes, China's environmental issues have aroused great concern among all walks of society, and it is necessary to examine whether FDI truly contributes to an improvement in the quality of China's economic growth.

In such a severe environmental crisis, is the pollution shelter hypothesis exists in China or not? If so, what are the differences in the inhibitory effects of environmental regulation on FDI? The answers to this series of questions need to be further examined. In contrast to most existing studies that adopt a regional or inter-regional perspective, the present research paper forms judgments that are situated within an empirical and industrial sector-level analysis, particularly as environmental pollution is largely caused by industrial production. As such, the research offers a more objective and authentic study of the establishment of pollution in China as well as of the impact of environmental regulation on the import of foreign capital with an emphasis on the industrial sector. 


\section{Literature review}

Walter and Ugelow (1979) proposed the pollution haven hypothesis which posits that polluting companies tend to establish factories in countries or regions with lower environmental standards. According to traditional trade theory, a country should produce and export products which comparative advantages as high environmental regulation will increase the cost of pollution control for enterprises. As such, Brand and Taylor (1997) highlighted that companies operating within countries with lower environmental standards benefit from cost advantages, and specialize in the production of pollution-intensive products. In some developing countries, governments may actively seek to reduce environmental standards to attract foreign direct investment, thereby transforming the country into a 'pollution paradise'. Zarsky (1999) suggested that to attract FDI through reduced environmental regulation standards, which encourage a race on the part of developing countries to attain the lowest environmental standards, environmental regulation has in fact inhibited the flow of FDI to regions with higher environmental regulation. Some academics who support the pollution haven hypothesis believe that environmental regulation has a significant negative impact on the location selected by new companies. For example, Garofalo and Malhotra (1995) and List et al. (1999) supported the findings of investment research examining the US industrial sector and manufacturing companies. Cole and Elliot (2005) found that capital abundance and lower environmental regulation standards constitute two conditions for the formation of pollution havens. Based on panel data from the US from 1977 to 1994, Keller and Levinson (2002) found that environmental regulation has a significant negative effect on FDI inflows. Chung (2014) utilized Korea's empirical analysis of panel data from 2000 to 2007 and found that South Korea tends to invest in some countries with weaker environmental regulation, thus supporting the asylum hypothesis. Cai et al. (2016) used the difference in differences (DID) technique to empirically analyze the relationship between environmental regulation and FDI, the findings of which revealed that strict environmental regulation inhibits the inflow of FDI. He (2006) and Cole et al. (2008) 
examined the finding that China's FDI policy supports the pollution shelter hypothesis and showed that environmental regulation inhibits the inflow of FDI. Liu et al. (2009) found that environmental regulation has a negative impact on the distribution of FDI. Furthermore, this impact was greater for mid and western regions compared to the eastern region. Qing (2013) homogenized environmental regulation variables and used the two-stage least-squares method to analyze the relationship between weak environmental standards and cost comparative advantages. The results demonstrated that weak standard controls play an important role in attracting FDI.

Other academics believe that environmental regulation has neither any effect nor a positive effect on the choice of location by FDI companies. For example, Levinson (1996) examined the impact of six environmental regulation variables (i.e., free index; green index; aggregate abatement cost; monitoring employment; industry abatement cost; business tax) on the location chose by new companies and found that the environmental regulation variables of just two countries were significantly negative. In addition, every 95 percent increasing in environmental regulation standards, the likelihood of Foreign Direct Investment is reduced by only 1.5 percent. McConnell and Schwab (1990) studied the impact of nine variables (i.e., three types of regulatory intensity measures including country level non-attainment variables, industry-specific state variables, and general state environmental regulatory measures. The specific nine variables included: Nonattain, Nonattain82, Extend, Ozone, Days, Opcost, Topreg, PACE, and FEES) that measure the influence of environmental regulation and standards on the chosen investment location of automotive companies. Only one variable was shown to exert a significantly negative influence, and a $20 \%$ increase in the variable decreases the probability of investment by $0.1 \%-0.4 \%$. Eskel and Harrison (2003) used four-digit industry-level panel data from the U.S. and four developing countries to conduct an empirical analysis and the result showed that environmental regulation promotes the introduction of FDI. Kahouli (2014) used data from 14 home countries, 39 host countries, and 6 regional trade agreements (i.e., 
EU(15), NAFTA, ASEAN, Mercosur, AMU, and EUROMED) related to the period 1990 to 2011. By adopting static and dynamic gravity equations to study the bidirectional relationship between environmental regulation and FDI, they found that environmental regulation exerted a positive effect on FDI. The study conducted by Rock (2002) failed to support the pollution haven hypothesis and suggested that environmental regulation has no impact on the flow of FDI. Dean et al. (2009) estimated conditional logic and nested logic models using new data sets utilizing information from a sample of equity joint venture projects, effective environmental levies on water pollution, and estimates of Chinese pollution-intensity for three-digit ISIC (International Standard Industry Classification) industries. Results from 2886 manufacturing joint venture projects during 1993-1996 showed that FDI from developed countries was positively associated with China's environmental tax rate. Jianhong and Lei (2007) found a regional difference with respect to the relationship between environmental regulation and FDI in China, showing a positive correlation in the eastern region and a negative correlation in the mid and western regions. Changfu et al. (2016) added environmental regulation variables into the framework for Dixit and Stiglitz monopolistic competition market model, and also concluded regional differences that could be attributed to a cost perspective. In addition, Ying and Xiang (2007), Zeng (2010), and $\mathrm{Wu}$ et al. (2010) also found that while environmental regulation has a weaker impact on China's overall FDI fluctuations, environmental regulation in different regions was shown to exert an influence on FDI, thus suggesting the regional heterogeneity of FDI. Moreover, industry heterogeneity may be observed between environmental regulations and the inflow of FDI in China. Yu (2011) researched 20 pollution-intensive industries including coal mining and washing, oil and gas extraction, ferrous metal mining, non-ferrous metal mining, and rubber products etc. and found that Chinese environmental regulation has no significant effect on direct investment in some companies. Yu and $\mathrm{Hu}$ (2016) subdivided industries in terms of pollution levels, and highlighted that environmental regulation has always negatively impacted upon the technological and innovative 
capabilities of high-polluting industries, promoted the innovation capability of medium-polluting industries, and shown a ' $U$ ' shape during periods of technological innovation by low-polluting industries.

Regarding the study on the relationship between environmental regulation and the introduction of FDI in China, whether due to cost factors, environmental regulation has inhibited the introduction of FDI, or considered trade factors, factor endowments, and the Porter hypothesis, environmental regulation has promoted the introduction of FDI. The difference between the two results may be due to the differences in the control variables. However, the researching is embedded within a national, regional, and industrial comparative theoretical analysis, and focuses less on the management costs incurred by the enterprise. Thus, the following problems are encountered in the process of examining how environmental regulation affects the ability to attract FDI. First, the existing literature fails to reflect a set of unified theoretical assumptions. As such, there are differences in terms of the selection of control variables. Second, a limited body of literature has focused on the application of game theory in order to research the impact of environmental regulation on the ability to attract FDI. Based on the Delegate-agent Framework, the regulatory Game between companies, managers, and regulators promotes FDI introduction through upgrading technology and the creation of new contracts between managers and enterprises. It offers significant theoretical support for the view. Third, existing literature places less emphasis on the management costs of foreign-related companies. Foreign-funded enterprises are faced with changes to the host operating environment, including host industrial policies, the host economic scale, and degree of marketization of capital inflows. All these changes will influence the management cost.

In light of such variables, the current paper seeks to address the foregoing issues. This study may offer novel insight into three particular issues. First, based on the extended game model of principal-agent regulation, the present study constructed a 
simultaneous equation system to analyze the time dynamic effects of environmental regulation on FDI in the Chinese industry, and specifically introduced management costs in order to evaluate the effect of environmental regulation on FDI within the industrial sector. Second, this study utilizes panel data from Chinese industrial companies related to the period 2005 to 2014 and adopts the three-stage least squares analysis method of simultaneous equations to carry out an assessment of the relationship between environmental regulation and FDI industry selection. The result shows that the upgrade of environmental regulatory standards will promote technological innovation within the Chinese industrial. As a result, such innovation will attract additional foreign capital, and the influx of large amounts of capital will once again stimulate technological progress. There is a circular interaction effect between the promotion of technological innovation and the capacity to attract foreign capital. More specifically, the implementation of new environmental policies will aggravate the game between managers and enterprises. It is deemed favorable to increase management coordination and minimize internal divergence within the industry, as this proves most conducive to organizational innovation and technological innovation, thereby encouraging FDI. Third, as revealed in the empirical analysis of phases and industries, the increase in environmental regulatory standards will elicit a 'compensation effect' for technological innovation. However, at the high-tech industry level, a negative effect may result in terms of technological innovation. Phase analysis reveals that FDI may be squeezed out by domestic capital, as foreign capital will select high-tech industrial enterprises with strong technological and innovative capabilities.

\section{Theoretical Framework}

This study draws on the assumptions of three behavioral entities (Ambec and Barla, 2002) including enterprises, managers, and enterprise regulators, the latter of which consist in principals, managers as agents, and environmental regulations representing exogenous conditions. For the purposes of the analysis, this study adopts 
the theoretical assumption that all Chinese industrial companies operate within a commissioned-agent business structure in order to further examine the choice of industry for FDI in China.

The foreign companies initially invested $I$ in $\mathrm{R} \& \mathrm{D}$ with the aim of developing product innovation, producing a technology with a fixed production cost $\alpha(\alpha \square\{l, h\}$ $\Delta \alpha=h-l>0$, information pertaining to the exact cost of the technology could be restricted to managers). The probability that managers select $l$ as the technical cost proposed is $p(I)$, and the technical probability function is quasi-concave $(p(0)=$ $\left.0, p^{\prime}>0, p^{\prime \prime}<0, p(\infty)=1, p(l)+p(h)=1\right)$. To simplify the model, it is assumed that no environmental pollution occurs when technology $l$ is utilized and reflected in the form of a low production cost. However, as technology $h$ is used to carry out production activities, the process of production generates environmental pollution, which is indicated by a quasi-convex function $d(q)$ on the yield $q$. It is assumed that $\forall q \in[0,+\infty)$, let $d(0)=0, d^{\prime}>0, d^{\prime \prime} \geq 0$. When the product is produced, the cost paid by the manager is $\alpha q$ and the salary paid from the foreign company to the manager is $w$. Therefore, the utility of the manager is expressed as $U_{M}(w-\alpha q)$. At this point, the company's operating profit from production is expressed as $R(q)$ and the income function reflects the decreasing property of the marginal return $\left(R(0)=0, R^{\prime}>0, R^{\prime \prime}<0\right)$. The utility of foreign companies is expressed as $U_{E}(R(q)-w-I)$, and the sum of the private surplus for both enterprises and managers is denoted by (1) in the production chain.

$$
\eta(q, \alpha)=\pi(q, \alpha)-I=R(q)-\alpha q-I
$$

We assumes that, under the effective production level, the production number $q_{\alpha}^{*}$ generates a maximization of private total surplus. Regulators within the economic system restrict the output from companies by setting the highest environmental 
288 pollution value $\bar{d}(q)$ Their behavioral goal is to maximize the overall welfare of the society. The overall social welfare is defined as the difference between the total private surplus and the environmental pollution value as denoted by $\eta(q, \alpha)-d(q)$. When the technical cost is $\alpha=h$ (or $\alpha=l$ ), the effective yield level for maximize social welfare is $q_{h}^{0}<q_{h}^{*}\left(q_{l}^{0}=q_{l}^{*}\right)$.

When there is no environmental regulation, companies and managers would carry on the unregulated Game. The enterprise initially invests $I$ and submits the original contract to the manager $\left\{w_{\alpha}, q_{\alpha}\right\}_{\alpha=l, h}$, which managers can accept or reject. Technology with a fixed production cost of price $\alpha$ is utilized to represent information privy to the manager, and the manager submits technology cost of price $\bar{\alpha} \in\{l, h\}$ to the enterprise. At the same time, the enterprise puts forward a new contract $(w, q)$ in accordance with the technical information provided by the manager. If the manager is in agreement, the revised contract will come into effect: Otherwise, the original contract will be enforced. Finally, the companies take operational and production decisions and remunerate the manager in accordance with the contract. In the course of 'the Game', the managers have limited responsibility for the business. The utility of managers in conducting production is not less than the utility of not carrying out any output activity.

Let us denote $\left\{I^{U},\left\{w_{\alpha}^{U}, q_{\alpha}^{U}\right\}_{\alpha=l, h}\right\}$ to express the perfect Bayesian equilibrium allocation of this game. The equilibrium Game has no less of generality in considering initial contracts that are not renegotiated along the equilibrium path i.e., renegotiation-proof contracts. It can be easily observed that the equilibrium renegotiation-proof contract must be separating and lead to a maximization of production levels. Thus, an equilibrium solution must be sought with respect to enterprise investment $I^{U}$ and manager compensation $\left\{w_{\alpha}^{U}\right\}_{\alpha=l, h}$ : 


$$
\max _{I,\left\{w_{\alpha}\right\}_{\alpha=l, h}} E\left[R\left(q_{\alpha}^{*}\right)-w_{\alpha} \mid I\right]-I
$$

$$
w_{l}-l q_{l}^{*} \geq 0
$$

$$
\text { S.t. } \quad w_{h}-h q_{h}^{*} \geq 0
$$

$$
w_{l}-l q_{l}^{*} \geq w_{h}-l q_{h}^{*}
$$

$$
w_{h}-h q_{h}^{*} \geq w_{l}-h q_{l}^{*}
$$

The first two conditions (3) and (4) are prior participation restrictions to ensure that the manager has limited liability. The latter two conditions (5) and (6)are incentive compatibility conditions, which stipulate that the manager prefers to report true private information (i.e., technical costs).

$$
w_{l}^{U}=\Delta \alpha q_{h}^{*}+l q_{l}^{*}
$$

(1) The equation7 indicates the manager's salary that is awarded by the enterprise upon adoption of the technology $I$ (The enterprise induces managers to report true technical cost information and $\Delta \alpha q_{h}^{*}$ expresses information rent). (2) The manager's

Define the R\&D investment with respect to the marginal income from the enterprise's investment: Enterprises prefer to pay information rent as the management cost, which is denoted by $I^{U}$ and shown by equation 8 .

There are two differences between the non-regulated game and the regulated game. First, within the regulatory game framework, the manager must simultaneously (1) $p\left(I^{U}\right)=I^{U} / A=I^{U} / I^{U^{*}}$, in this formula, $A=\eta\left(q_{l}^{*}, l\right)-\Delta \alpha q_{h}^{*}-\eta\left(q_{h}^{*}, h\right)$ stands for R\&D investment $I^{U^{*}}$ at the optimal output level, and $I^{U}$ has a positive correlation with output $q$, that is, the more R\&D investment, the higher the production efficiency. 
333 report the same technical $\operatorname{cost} \bar{\alpha} \in\{l, h\}$ to both the enterprises and the regulators, 334 and the report is made publicly available in the system. Second, within the regulatory 335 Game framework, the regulator set the particular upper limit $\bar{d}$ of environmental 336 pollution. It is actually equal to the limit for maximum output $q_{\alpha}^{R}$ for a 337 corresponding technological level.

338 When environmental regulation exists, companies, managers, and regulators play 339 a regulatory game framework. The enterprise initially invests $I$ and puts forward the 340 initial contract $\left\{w_{\alpha}, q_{\alpha}\right\}_{\alpha=l, h}$ to the manager. The technical cost $\alpha$ denoted the 341 manager's private information and, simultaneously, the manager reports the 342 technology $\bar{\alpha} \in\{l, h\}$ to the enterprise. Subsequently, the regulator sets the upper 343 environmental pollution limit $\bar{d}\left(q_{h}^{0}\right)$, and the company proposes a new contract $344(w, q)$ based on the technical information provided by the manager and the 345 environmental pollution limit. If the manager is in agreement, the new contract comes 346 into effect: Otherwise, the initial contract becomes effective. The company takes 347 operational and production decisions and pays the manager's salary in accordance 348 with the contract in force. At the time, the Bayesian perfect equilibrium of this 349 asymmetric information game is defined as $\left\{I^{R},\left\{w_{\alpha}^{R}, q_{\alpha}^{R}\right\}_{\alpha=l, h}\right\}$. In implementing the 350 regulator's behavioral strategy in the Game system, companies and managers will 351 always make two kinds of output choices $q_{l}^{R}=q_{l}^{*}$ and $q_{h}^{R}=q_{h}^{0}$. Hence, the 352 regulator's dominant strategy is to set the upper limit for environmental pollution $353 \quad \bar{d}=d\left(q_{h}^{0}\right)$.

(1) When adopting technology $L$ (the enterprise induces the manager to report 355 the true technical cost information, $\Delta \alpha q_{h}^{0}$ expresses the information rent), the 356 manager's salary is paid $w_{l}^{R}=\Delta a q_{h}^{0}+l q_{l}^{*}$ (2) When adopting technology $h$, the 
manager's salary is paid $w_{h}^{R}=h q_{h}^{0}$ and the enterprise need not pay information rent (3)The enterprise's R\&D investment $I^{R}$ satisfies equation9.

$$
p^{\prime}\left(I^{R}\right)\left(\eta\left(q_{l}^{*}, l\right)-\Delta a q_{h}^{0}-\eta\left(q_{h}^{0}, h\right)\right)=1
$$

The following is a summary of the foregoing theoretical analysis:

The firstly, according to the regulatory game framework, as output $q_{h}^{0}$ replaces $q_{l}^{*}\left(q_{h}^{0}<q_{l}^{*}\right)$, the information rent $\Delta \alpha q_{h}^{0}$ paid by enterprises will decrease, and the foreign company's private surplus $U_{E}\left(R\left(q_{h}^{0}\right)-w-I\right)$ will also diminish. Both aspects exert a clear positive effect on corporate $R \& D$ investment (according to the compactness of the $\quad p$ function), and it is also possible to deduce $I^{R}>I^{U}$.

The secondly, according to the regulatory game framework, when output $q_{h}^{0}$ replaces $q_{l}^{*}\left(q_{h}^{0}<q_{l}^{*}\right)$, the expected return of the firm is uncertain, as management costs change and the total private(manager and enterprise) residual changing. If $I^{R}$ maximizes the expected return of the firm in accordance with the regulatory Game framework i.e., equation(10), then a sufficient condition for maximizing the foregoing proceeds is shown by equation(11).

$$
\begin{gathered}
E\left[R\left(q_{\alpha}^{R}\right)-w_{\alpha}^{R} \mid I^{R}\right]-I^{R} \geq E\left[R\left(q_{\alpha}^{R}\right)-w_{\alpha}^{R} \mid I^{U}\right]-I^{U} \\
E\left[R\left(q_{\alpha}^{R}\right)-w_{\alpha}^{R} \mid I^{U}\right] \geq E\left[R\left(q_{\alpha}^{U}\right)-w_{\alpha}^{U} \mid I^{U}\right] \\
\frac{\mathrm{p}\left(I^{U}\right)}{1-\mathrm{p}\left(I^{U}\right)} \Delta \alpha \geqslant \frac{\pi\left(q_{h}^{*}, h\right)-\pi\left(q_{h}^{0}, h\right)}{q_{h}^{*}-q_{h}^{0}}
\end{gathered}
$$

The aforementioned formula can be expressed as equation (12). The left side of the inequality expresses the information rent saved, and the right side denotes the enterprise's lost profit at existing environmental regulatory conditions. Since $\eta(q, h)$ 
is concave, i.e., $q_{h}^{*}>q_{h}^{0}$, producing equation(13),

$$
\pi\left(q_{h}^{*}, h\right)-\pi\left(q_{h}^{0}, h\right) \leqslant \frac{\partial \tau\left(q_{h}^{0}, h\right)}{\partial_{1}\left(q_{h}^{*}-q_{h}^{0}\right)}
$$

and as $q_{h}^{o}$ satisfies $\frac{\partial \tau\left(q_{\mathrm{h}}^{\mathrm{o}}, h\right)}{\partial}=d^{\prime}\left(q_{\mathrm{h}}^{\mathrm{o}}\right)$, then equation(14) is obtained.

$$
\frac{p\left(I^{U}\right)}{1-p\left(I^{U}\right)} \Delta \alpha \geqslant d^{\prime}\left(q_{h}^{o}\right)
$$

Until this point, there has always been sufficiently low or marginal environmental pollution to satisfy the above inequality.

Based on the analysis summary of the foregoing theoretical the following conclusion can be reached: Environmental regulation and corporate management costs will increase the R\&D investment ( $I^{R}>I^{U}$ ) for foreign companies, and it will also increase the expected returns of companies. Therefore, this paper proposes two testable theoretical hypotheses:

Hypothesis 1: Environmental regulation will increase the R\&D investment of enterprises, and it will influence FDI industrial options in the Chinese industry through the technological innovation effect.

Hypothesis 2: Environmental regulation and the management costs incurred by enterprises simultaneously affect technological innovation, and in turn, affect the transfer of FDI across industrial sectors through the enterprise's profit.

\section{Model and variable}

\subsection{Model Construction}

When demonstrating the relationship between environmental regulation and technological innovation, many transmission mechanisms are logical and interactive. This study is based on an analysis of the aforementioned theoretical framework and the testable hypotheses proposed. First, this paper examines the impact of 
environmental regulation on FDI in the Chinese industry while considering the way in which environmental regulation can promote technological innovation. Second, in addition to the game cost incurred by enterprises and managers (the article uses MC indicating management cost instead of the explanation) in an effort to comply with environmental regulations and standards, environmental regulation further exerts an influence on enterprise innovation which, in turn, affects the FDI input of foreign companies. The key, the situation in which external conditions such as environmental regulation intervenes the regulation game system, overcomes the malleability of enterprise organizations within the industry. At the same time, the internal management costs of the enterprise can also overcome organizational inertia. Based on the hypothesis outlined, this paper develops a technical equation to evaluate the effect of environmental regulation and management cost on FDI in the Chinese industry. The risk assessment of FDI investment reveals that foreign companies prefer to invest industries with which they are familiar, since FDI input for the current year is related to FDI input for the previous year. Thus, the lag (1) of FDI was added to the foreign investment measurement equation.

At this point, environmental regulation is considered an exogenous variable, and management costs and industry profits are permitted to form part of the mechanism control system. Henceforth, this study evaluates the effect of environmental regulation, technological innovation, and foreign capital selection in the industry through the application of behavioral equations that constitute a simultaneous equation system. At the same time, in pursuance of data analysis stability, this paper adopts the full logarithm processing method for the latter empirical analysis of data.

$$
\begin{aligned}
& R \boldsymbol{\&} D_{i, t}=\beta_{0}+\beta_{1} F D I_{i, t}+\beta_{2} E R S_{t}+\beta_{3} M C_{i, t}+\varepsilon_{2 i, t} \\
& F D I_{i, t}=\alpha_{0}+\alpha_{1} F D I_{i, t-1}+\alpha_{2} R \& D_{i, t}+\alpha_{3} P R 0_{i, t}+\varepsilon_{i, t}
\end{aligned}
$$

In the aforementioned formulas, industry is denoted by $i$, and the period is expressed as $t$. The R\&D meteorological equation (15) expresses the technological 
innovation equation, which means that technological innovation is determined by current direct investment $(F D I)$ from foreign companies, environmental regulation level (ERS), and industry management costs $(M C) . \varepsilon_{i, t}$ represents a random disturbance term. The equation (16) expresses foreign capital, which is determined by the lag-one $\left(F D I_{-1}\right)$ foreign direct investment, technological innovation $(R \& D)$, and current industry profit $(P R O)$. This constitutes a structural simultaneous equation system that describes the dynamic choices of industry for FDI following the introduction of environmental regulation and management costs.

Under this situation, and without considering the existence of heterogeneity in the random error term or sequence correlation, the system panel moment estimation method (SYS-GMM) is used for the dynamic panel model in order to estimate the parameters, thereby making it more robust and realistic. If only a single equation estimation is used, the result may neglect to reflect the relationship between the equations. Therefore, it is more efficient to estimate all equations as a whole. In a sense, Three stage least square method (3SLS) is an estimation method that combines two stage least square method (2SLS) and seemingly unrelated regression model (SUR) (Chen, 2016).

\subsection{Explanation of indicators}

(1) Environmental Regulation Level (ERS) is variable name for environmental regulation in the paper. Environmental regulation is a national or regional standard that is developed for the purpose of environmental protection, or the cost of governance. The comparative representative literature uses different methods to measure the intensity of environmental regulation. As the level of economic development improves, income levels continue to rise and environmental regulations will become more stringent. As such, some scholars adopt per-capita GDP as a proxy for this indicator (Antweiler et al. 2001). There are also some scholars who employ quantitative indicators of environmental governance costs as surrogate variables (Cheng, 2011). In the present study, the environmental regulation level (ERS) 
encompasses emissions of waste water, waste gas, and general solid waste divided by the total industrial output value of each industry, thus resulting in the discharge volume of the unit output value for each industry, which are then averaged. The specific processing steps are as follows: First, the unit output value of each pollutant in each industry is calculated.

$$
U E_{i j}=E_{i j} / Y_{i}
$$

$U E_{i j}$ expresses the pollution emissions $j$ per unit of production value of pollutants in the given industry $i . E_{i j}$ denotes the pollution emissions $j$ of pollutants in the given industry $i$, and $Y_{i}$ represents the industrial output value of industry $i$.

Second, the average of the total of the three types of pollutants is calculated in order to obtain the environmental regulation level $E R S_{i}$ for each industry.

$$
E R S_{i}=\frac{1}{n} \sum_{j=1}^{n} U E_{i j}
$$

(2) Foreign direct investment (FDI). The traditional FDI theory studies the location selection of FDI, and the effect of environmental regulation on the choice of FDI location is always a thorny issue. Thus, it is a new direction for research moving away from a location-based analysis towards an industry -based analysis. This study used foreign capital as an explanatory variable and selected the sum of foreign capital and Hong Kong, Macao and Taiwan from the paid-in capital of industrial enterprises above a designated size. Data were condensed to the Chinese fixed asset price index of 2005 which represents the base period.

(3) Technological Innovation (R\&D). The degree of technological innovation activity depends on the level of investment in technological innovation, and to a certain extent, it can be reflected by a company or industry's R\&D expenditure (Wang and Wang, 2011). A large body of existing literature uses R\&D input as a proxy variable for measuring innovative capabilities. The technical innovation index of this 
paper selects the internal $R \& D$ expenditures of industrial enterprises above a designated size, and data are reduced to the Chinese industrial product ex-factory price index of 2005 which represents the base period.

(4) Industry profits (PRO). The profit of an industry can reflect whether the industrial company's operating conditions are good or whether it has potential for development, thereby providing an important referential indicator for capital investment decisions. FDI will inevitably be affected by an industry's profits when making industry selections. If the industry enjoys a substantial profit, greater capital FDI accumulates in the industry. Based on this premise, the current study selected the total profit of industrial enterprises above a designated size, and used the index of China's industrial product prices for 2005 which represents the base period and condenses the data.

(5) Management cost (MC). Each industry faces changes within the business environment, the host country's economic policies, development level, and marketization level. Such changes affect the management costs of the industry. Changes in environmental regulation policies directly affect the management costs of business operations, and changes in management costs also indirectly affect the output and profits of enterprises which, in turn, affect the ability to attract FDI. The indicator selects the management costs of industrial enterprises above a designated size and uses the Chinese industrial product ex-factory price index of 2005 which represents the base period and reduces data.

The research objects are industrial enterprises above a designated size in different industries, and the data are derived from the Statistical Yearbook of China's Industrial Economy, the Statistical Yearbook of China's Science and Technology, the Yearbook of China's Environmental Statistics, and the Statistical Yearbook of China. All data relate to the period 2006-2015. According to Chinese industry classification standards, this study identified 35 representative industrial sectors. An analysis was carried out on dynamic panel data across 10 years in these 35 industrial sectors. The 


\begin{tabular}{|c|c|c|c|c|}
\hline Variable & Metrics & Obs & Mean & Symbol \\
\hline $\begin{array}{c}\text { Environmental } \\
\text { Regulation Level }\end{array}$ & $\begin{array}{l}\text { Unit output value average amount of } \\
\text { effluent levy of Waste water, waste } \\
\text { gas and solid waste }\end{array}$ & 350 & 2.60 & $E R S_{t}$ \\
\hline Foreign Capital & $\begin{array}{l}\text { paid-in capital of industrial enterprises } \\
\text { above designated size from foreign } \\
\text { investors, Hong Kong, Macao and } \\
\text { Taiwan/ One hundred million yuan }\end{array}$ & 350 & 685.19 & $F D I_{i, t}$ \\
\hline $\begin{array}{l}\text { Technological } \\
\text { Innovation }\end{array}$ & $\begin{array}{c}\text { R\&D Funding of Industrial } \\
\text { Enterprises above Designated Size / } \\
\text { One hundred million yuan }\end{array}$ & 350 & 125.08 & $R \& D_{i, t}$ \\
\hline Industry Profits & $\begin{array}{c}\text { Total profit of industrial enterprises } \\
\text { above designated size / One hundred } \\
\text { million yuan }\end{array}$ & 350 & $\begin{array}{c}1106.6 \\
0\end{array}$ & $P R O_{i, t}$ \\
\hline $\begin{array}{c}\text { Management } \\
\text { Costs }\end{array}$ & $\begin{array}{c}\text { Management costs of industrial } \\
\text { enterprises above designated size / } \\
\text { One hundred million yuan }\end{array}$ & 350 & 667.87 & $M C_{i, t}$ \\
\hline
\end{tabular}

deviation resulting from the caliber of different statistics has been systematically adjusted. Descriptive statistics of variables are shown in the Table 1.

Table 1. Descriptive statistics of variables

\section{Empirical Analysis}

This study uses Stata 12.0 to estimate the foregoing simultaneous equation system by generalized moment estimation. To enhance the readability of data and remain original economic significance of the retention variables, all indicators for all equations are digitized. Two endogenous variables are featured in the simultaneous equation system, namely, FDI and R\&D variables. Tour pretest variables include FDIt-1, PRO, ERS, and MC. Each equation contains an endogenous explanatory variable that which excludes two predecessors, and the system of equations is over-identified. Therefore, this study aimed to develop a full-sample, sub-period, and industry-by-industry estimation of the simultaneous equation system. In view of the validity of the three-stage least squares method, the robustness test was performed on 
523 the full sample model after full-sample, sub-period and industry-by-industry 524 estimation.

\subsection{Benchmark regression}

Based on the Table 2, OLS estimation of the two equations within the simultaneous systems revealed that R\&D expenditure had no significant effect with respect to the inflow of foreign capital represented in the foreign capital equations. With regard to the technological innovation equation, environmental regulation was shown to exert a positive effect on R\&D expenditure at the $10 \%$ significance level. Considering that the endogenous variables in the simultaneous equation system appear on the right side of the equation and each explanatory variable is related to the random disturbance term, it can be reasoned that the results of the ordinary least squares estimation will be biased and inconsistent. Other estimation methods for single equations (Instrument Variable Method IV, Two-stage Least Squares Method 2SLS) fail to take account of the internal relations of the simultaneous equation systems. Therefore, it is necessary to use the Three-stage Least Squares Method (3SLS) in the system estimation to yield a consistent and progressively effective estimator in a multi-equation system. By estimating the 3SLS simultaneous equation system for 35 samples of industries above a designated size, the researchers could find that each explanatory variable is more significant in the system based on the Table 2.

For the technological innovation equation, FDI, the level of environmental regulation, and the cost of corporate management all have a significant positive impact on Chinese industrial technology innovation at the industry level from the Table 2 results. It can be seen from the Table 2 estimated results of the whole sample of simultaneous equations that there is a positive interaction between R\&D funding and foreign capital flows. With every $1 \%$ increase in foreign capital, the industry's R\&D expenditure will increase by $0.176 \%$. Chinese foreign capital is sourced mainly from developed countries in Asia and from Hong Kong, Macao and Taiwan as well as from the US Investors place a greater emphasis on the impact of technological 
551 innovation on the endogenous development of a company or industry. Furthermore, 552 when China avails of FDI, it benefits not only from the use of capital but from the 553 introduction of technology. Every $1 \%$ increase in the level of environmental 554 regulation (i.e., if the average value of the unit output value for the three types of 555 waste increases by $1 \%$ ), the R\&D expenditure will increase by $0.02 \%$. While this 556 effect is significant, the increase is marginal. It may be observed that the logical 557 mechanism is weak with regard to the overall negative impact on Chinese industrial $558 \mathrm{R} \& \mathrm{D}$ to hedge against environmental pollution due to the increase in the volume of 559 pollutant emissions. This finding may also be attributed to the country's imperfect 560 mechanism for the development and implementation of environmental governance. In 561 addition, Chinese industrial enterprises have given little consideration to 562 environmental regulation during the period of technological innovation, and have not

563 taken sufficient responsibility for addressing environmental pollution over the course of the development process. Game behavior between managers and enterprises will increase the management costs of the company's operations for internal coordination. With respect to the environmental regulation game, associated management costs will become more prominent due to the implementation of a new policy, and it will be necessary for managers and companies to re-contract the game. The increasing cost of enterprise management can improve the degree of activity within a company's internal coordination and organizational structure and strengthen the FDI spill-over effect by increasing $\mathrm{R} \& \mathrm{D}$ expenditure. The $\mathrm{R} \& \mathrm{D}$ expenditure spill-over effect exceeds and compensates for the loss in profit caused by the increase in management costs. Therefore, increasing management costs will directly promote the funding of technological innovation.

Table 2. Total Sample Estimation Results of 35 Industrial Enterprises Above a Designated Size

\begin{tabular}{llllll}
\hline \multirow{2}{*}{ Variables } & \multicolumn{2}{c}{ LnR\&D } & & \multicolumn{2}{c}{ LnFDI } \\
\cline { 2 - 3 } \cline { 4 - 5 } & OLS & 3SLS & & OLS & 3SLS \\
\hline
\end{tabular}




LnFDI $\quad 0.168^{* * *} \quad 0.176^{* * *}$

LnFDI(-1)

LnR\&D

LnPRO

ERS

LnMC

C

$-5.741^{* * *}$

$(-25.24)$

$-5.802^{* * *}$

$(-29.55)$

$1.392^{* * *}$

29.55)

Observation

Groups

$\begin{array}{lll}\mathrm{R}^{2} & 0.855 & 0.849\end{array}$

Adjusted R ${ }^{2}$

0.854

304

$0.481^{* * *}$

$0.85^{* * *}$

(2.85)

$0.109^{* * *}$

$-0.139^{* * * *}$

$(-3.22)$

$(-2.02)$

$(-3.22)$

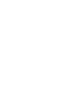
(66.32)

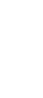

$$
0.976^{* * *} \quad 0.951^{* * *}
$$

$-0.626^{* *}$

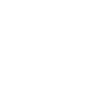

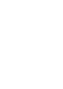

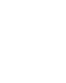


select the industrial sector. Foreign capital will increase by $1 \%$ for the previous period, and by $0.951 \%$ for the current period. With respect to the investing options for Chinese industrial sectors, foreign investors place a greater emphasis on the coherence of Chinese industrial economic policies, and will form a wider pool of industries in order to avoid international investment risk in terms of industry differences. Based on analysis of the full sample, every $1 \%$ increase in R\&D expenditure for all 35 industrial sectors will cause the entire industry to absorb $0.109 \%$ of foreign capital. While forming industry choices, foreign investors will view technological innovation as an important indicator to assess the potential investment return from a target industry. As R\&D funding and investment within an industry increases, the technological and innovative capabilities of that industry become strengthened, thereby reinforcing the endogenous driving force for development which, in turn, enhances market potential and the industry's attractiveness to investors, particularly international investors. These factors has already showed an significant performance throughout the entire Chinese industrial sector. Industry profits will also directly affect the amount of foreign capital. Equation tests show that every $1 \%$ increase in the total profit of all Chinese industrial enterprises selected will lead to a decrease of $0.139 \%$ in the foreign capital of the corresponding industry for the current period. The negative impact of industry profits on foreign capital exceeds the industry R\&D positive effect of external capital attraction for investment. Profits from the Chinese industrial sector have a crowding-out effect on foreign capital. When the profits of domestic industrial enterprises are increasing and companies are continuously developing, despite their capital-intensive and technical requirements, such companies tend only to seek domestic capital. Furthermore, the demand for foreign technology is greater than the demand for capital. As such, a clear crowding-out effect on foreign capital will result. The validity of the market-for-technology policy has been demonstrated. 
and having conducted an empirical test using 3SLS, the researchers can conclude that enhanced levels of environmental regulation and increasing industrial management costs will significantly improve R\&D funds at the industry-level, and the investment in R\&D funds will also attract the inflow of foreign capital. To more comprehensively analyze the impact of environmental regulation on FDI sector selection, the current study empirically examines this relationship in terms of different periods and industries.

\subsection{Time heterogeneity analysis}

In 2008, the global financial crisis erupted and the negative impact of the economic crash gradually began to surface in 2009. Chinese industrial enterprises have incurred significant profit declines, and R\&D funds as well as foreign capital have been curbed accordingly. Therefore, this study divides the research period into two phases. The first phase examines the period 2005-2008. The second phase assesses the period 2009-2014. Three-stage least squares (3SLS) regression analysis was carried out for each phase.

With regard to the first phase (2005-2008), the test results of the technological innovation equation are very similar to the results obtained for the full sample and show that environmental regulation, management costs, and foreign capital exert a significant and positive impact on R\&D and the flow of FDI from the Table 3 results. However, with respect to the foreign capital equation, it is evident that neither R\&D funding nor industry profits indicate any impact on FDI. This may be due to the fact that, during this period, the Chinese industrial sector did not rely on technological innovation to attract FDI, and the profits generated from industry development did not produce a crowding-out effect on the inflow of foreign capital. At this stage, the inflow mechanism of FDI cannot be explained by technological innovation. In addition, the inflow of FDI is significantly related to the entry of foreign investors in the previous period. This indicates that FDI targets industries that enjoy a guaranteed market share in order to reduce risks. 
For the second phase (2009-2014), the results showed that the level of environmental regulation in the technological innovation equation was not significant in the Table3, and cannot explain the impact on R\&D funding. In recent years, China has increasingly emphasized innovation, and many areas are currently undergoing transformation and development. Many complex factors affect technological innovation, and it is possible that there are additional influential factors that impact upon the test results in terms of environmental regulation. With respect to the foreign capital equation, the test results are very similar to those obtained from the whole sample. Improved technological innovation has led to an increasing inflow of foreign capital, and the promotion of industry profits has, to some extent, squeezed foreign capital. The development and transformation of Chinese industrial enterprises, particularly in terms of technological innovation, has allowed such enterprises to seize opportunities and avail of resources on the international capital market. It is evident that such progress has also resulted in a significant crowding-out effect on foreign capital during periods of development and transformation.

Table 3 The 3SLS Estimation Results of 35 Industrial Enterprises above a Designated Size Difference phrase

\begin{tabular}{|c|c|c|c|c|}
\hline \multirow{2}{*}{ Variables } & \multicolumn{2}{|c|}{ LnR\&D } & \multicolumn{2}{|c|}{ LnFDI } \\
\hline & 2005 2008 & 2009 2014 & $2005 \sim 2008$ & 2009 2014 \\
\hline LnFDI & $\begin{array}{c}0.183^{* * *} \\
(4.12)\end{array}$ & $\begin{array}{c}0.174^{* * *} \\
(5.09)\end{array}$ & & \\
\hline LnFDI(-1) & & & $\begin{array}{l}0.903^{* * *} \\
(23.62)\end{array}$ & $\begin{array}{c}0.967^{* * *} \\
(42.39)\end{array}$ \\
\hline LnR\&D & & & $\begin{array}{l}0.117 \\
(1.44)\end{array}$ & $\begin{array}{c}0.117^{* * *} \\
(2.68)\end{array}$ \\
\hline LnPRO & & & $\begin{array}{l}-0.870 \\
(-1.00)\end{array}$ & $\begin{array}{c}-0.137^{* *} \\
(-2.52)\end{array}$ \\
\hline
\end{tabular}


ERS

$$
0.026^{* *} \quad 0.010
$$

$$
1.365^{* * *} \quad 1.379^{* * *}
$$

C

$$
-5.704^{* * *}
$$

$0.836^{*}$

$0.850^{* *}$

$(-14.28)$

Observation

Groups

100

304

100

170

$\mathrm{R}^{2}$

0.845

0.840

0.952

0.963

660

661

662

663

664

665

666

667

668

669

670

671

672

673

674

675

676

677

678

Note: ${ }^{* * *},{ }^{* *},{ }^{*}$ indicates significant at $1 \%, 5 \%, 10 \%$ level respectively. model brackets correspond to z-statistics for each explanatory variable. The data in the table were compiled using output from Stata 12.0 SE software.

\subsection{Analysis of industry heterogeneity}

This study classifies 35 industrial enterprises into four categories in accordance with the classification of Chinese industries developed by Wang et al. (2010), namely, resource-based industries, raw materials industries, general manufacturing industries, and high-tech industries. A separate empirical analysis was performed for each individual sector.

The resource-based industries include the production and supply of five major mining industries, electricity, gas, and water. The three wastes emissions factored into the analysis (ERS average $=4.02$ ) are much higher than the average (i.e., 2.60) for the 35 industries. In addition, $R \& D$ funding $(R \& D$ average $=20.93)$ is far less than the average (i.e., 125.08) for the 35 industrial sectors. Chinese resource-based industries are more pollution-intensive, and investment for technological innovation within the production sector is substantially weaker. However, the profits generated by these industries do not significantly differ from the average profits of the overall industry. With respect to the technological innovation equation, the level of environmental regulation in resource-based industries does not have a significant impact on R\&D 
funding based on the Table 4. Chinese environmental regulatory policies are largely command-and-control and impose 'external restraints' consisting in administrative orders that are too rigid and that tend to reflect a 'one-size-fits-all' framework for companies. Such restraints damage corporate efficiency and inhibit enthusiasm for technological innovation (Ma et al., 2011). However, the inflow of foreign capital will result in decreased investment in technological innovation by resource-based industries. With respect to the foreign capital equation, $R \& D$ funding still exerts a positive impact on the attraction of FDI. However, profit was not found to significantly affect the selection of FDI industries. The industry is more likely to have overly high market access thresholds due to the country's high degree of control over economic security.

The raw materials industry primarily produces some industrial primary products and semi-finished products, which are largely utilized in the production processes of general manufacturing and high-tech industries. The average value of the environmental regulatory variables in the raw material industry is 2.30 , which is much smaller than that of the resource-based industry, and the volume of pollutant discharge in this industry is small. At same time, the FDI, R\&D funding, and industry profits of the raw materials industry are slightly higher than the average level of Chinese industrial enterprises. With respect to the technological innovation equation, the results revealed that the level of environmental regulation has a positive effect on the industry's technological innovation under 1\% significance level in the Table 4 and suggests that an increase in environmental standards will stimulate technological innovation within this particular type of industry. The degree of stimulus is higher among the four types of industries, such that every $1 \%$ increase in the promotion of ERS leads to an increase of $0.112 \%$ in R\&D funding from the Table 4 results. The innovation space of the raw material industry in the production process still remains very large, and this type of industry is willing to improve production efficiency and product quality through innovation to mitigate the negative effect of environmental 
standards on the industry. With respect to the foreign capital equation, neither technological innovation nor industry profits impact upon foreign capital, a result comparable to that of resource-based industries.

The general manufacturing industry largely consists in food and clothing companies, which constitute an important part of the manufacturing industry in China. The average R\&D funding of general manufacturing industries is also very low, though higher than that of resource-based industries. The level of environmental regulation is slightly higher than that of the raw materials industry, albeit far lower than that of resource-based industries. The average value of foreign capital allocated to development of the industry is also lower than that of the entire industry. With respect to the technological innovation equation, all the explanatory variables have a significant impact on R\&D funding. However, environmental regulation variables and foreign capital contribute less to the promotion of $R \& D$ from the Table 4 results. To a certain extent, these findings reveal insufficient innovation within the Chinese general manufacturing industry, and at the very least suggest that there is still substantial room for improvement. The mechanism for promotion takes account of resource and technological stimuli concerning foreign capital, and the impact of domestic policies (i.e., environmental regulation policies etc.) exert some influence on innovation. In the long run, the sound environmental policy formulated by the government will not only improve pollution control technology, but furthermore advance technological progress (Ilhan Ozturk 2015; Zhang et al., 2011). With respect to the foreign capital equation, there no effective core explanatory variable was identified that can significantly analyze the relationship between FDI and industry selection. The general manufacturing sector is the type of industry which attracted large sums of Chinese private capital at the early stages, and these industries enjoy a mature portfolio of various Chinese natural capitals. Therefore, to a large extent, a clear crowding-out effect on foreign capital can be observed.

In terms of the high-tech industry, the foreign capital, industry profits, and 
management costs of the high-tech industry are two to three times greater than the average for industry as a whole. With respect to the technological innovation equation, environmental regulation variables have a significant negative impact on $R \& D$ funding, which is contrary to the Porter hypothesis based on the Table 4 results. The increasing costs incurred as a result of environmental regulation will directly affect Chinese R\&D funding in high-tech industries and hinder their technological innovation. This is due to the fact that the Chinese high-tech industry produces an average emission value (i.e., with respect to the three wastes analyzed) per unit production value average that is far less than the first three industry types described, a figure which is far less than the average level for the entire industry in China. When the level of environmental regulation for effluent levy is very low, the conclusion of Porter's hypothesis is not supported in China (Shen and Liu, 2012). However, this hypothesis has gained practical support for the raw materials and general manufacturing industries. The promotion of a standardized environmental regulation will reduce the innovation funds and result in a crowding-out effect of capital and investment which has a negative effect on technological innovation (Jiang et al, 2013). In terms of the foreign capital equation, the advancement of technological innovation will significantly attract foreign capital based on the Table 4 results, thereby contributing to the development of the Chinese high-tech industry, particularly as FDI places a greater emphasis on the impact of technological innovation and changes within the development of the industry. When foreign capital is invested in high-tech industries in China, technological innovation is regarded as an important indicator by which to measure the development of enterprises. In addition, industry profits have a significant crowding-out effect on FDI high-tech industry choices. However, the large profits generated by the development of the high-tech industry will directly attract a large influx of state-owned capital and domestic private capital, directly squeezing tightly-regulated foreign capital under the complicated Game strategies, where various types of capital participate in the development of the industry. 

by Industry

\begin{tabular}{|c|c|c|c|c|c|c|c|c|}
\hline \multirow[t]{2}{*}{ Variables } & \multicolumn{2}{|c|}{$\begin{array}{l}\text { Resource-based } \\
\text { Industry }\end{array}$} & \multicolumn{2}{|c|}{$\begin{array}{l}\text { Raw Materials } \\
\text { Industry }\end{array}$} & \multicolumn{2}{|c|}{$\begin{array}{l}\text { General } \\
\text { Manufacturing } \\
\text { Industry }\end{array}$} & \multicolumn{2}{|c|}{ High-tech Industry } \\
\hline & LnR\&D & LnFDI & LnR\&D & LnFDI & LnR\&D & LnFDI & LnR\&D & LnFDI \\
\hline \multirow{2}{*}{ LnFDI } & $-0.138^{* * *}$ & & 0.032 & & $0.087^{* * *}$ & & -0.068 & \\
\hline & $(-2.47)$ & & $(0.23)$ & & (3.64) & & $(-1.00)$ & \\
\hline \multirow{2}{*}{$\begin{array}{l}\text { LnFDI(- } \\
1)\end{array}$} & & $0.942^{* * *}$ & & $0.763^{* * *}$ & & $0.996^{* * *}$ & & $0.969^{* * * *}$ \\
\hline & & $(22.38)$ & & $(10.08)$ & & $(39.8)$ & & $(22.75)$ \\
\hline \multirow{2}{*}{ LnR\&D } & & $0.185^{*}$ & & 0.023 & & 0.099 & & $0.300^{* * *}$ \\
\hline & & (1.77) & & $(0.19)$ & & (1.03) & & $(4.06)$ \\
\hline \multirow{2}{*}{ LnPRO } & & -0.261 & & 0.122 & & -0.147 & & $-0.337^{* * *}$ \\
\hline & & $(-1.93)$ & & (1.18) & & $(-1.29)$ & & $(-4.66)$ \\
\hline \multirow{2}{*}{ ERS } & 0.14 & & $0.112^{* * * *}$ & & $0.033^{* * *}$ & & $-0.439^{* * *}$ & \\
\hline & $(0.57)$ & & $(2.74)$ & & $(4.51)$ & & $(-3.12)$ & \\
\hline \multirow{2}{*}{ LnMC } & $1.524^{* * *}$ & & $0.943^{* * *}$ & & $1.483^{* * *}$ & & $1.268^{* * *}$ & \\
\hline & (19.39) & & $(7.65)$ & & $(27.82)$ & & (17.47) & \\
\hline \multirow{2}{*}{$\mathrm{C}$} & $-5.789^{* * *}$ & $1.582^{* * *}$ & $-1.88^{* * *}$ & $0.648^{*}$ & $-5.913^{* * *}$ & 0.668 & $-2.700^{* * *}$ & $1.065^{* * *}$ \\
\hline & $(-12.83)$ & (2.4) & $(-3.16)$ & $(1.95)$ & $(-19.53)$ & $(1.27)$ & $(-8.59)$ & $(4.1)$ \\
\hline \multirow{2}{*}{\multicolumn{9}{|c|}{$\begin{array}{l}\text { Observat } \\
\text { ion } \\
\text { Groups }\end{array}$}} \\
\hline & & & & & & & & \\
\hline $\mathrm{R}^{2}$ & 0.865 & 0.898 & 0.686 & 0.822 & 0.885 & 0.972 & 0.968 & 0.975 \\
\hline 765 & \multirow{4}{*}{\multicolumn{8}{|c|}{$\begin{array}{l}\text { Note: }{ }^{* * *} \text { indicates a } 1 \% \text { significance level, }{ }^{* *} \text { indicates a } 5 \% \text { significance level, } \\
\text { indicates a } 10 \% \text { significance level; data in the model brackets correspond to }\end{array}$}} \\
\hline 766 & & & & & & & & \\
\hline 767 & & & & & & & & \\
\hline 768 & & & & & & & & \\
\hline
\end{tabular}


For the aforementioned four types of industrial enterprises, management costs, as an exogenous variable, have a significant and positive impact on $R \& D$ funding and attract FDI from the Table4 results. Management costs represent an agency indicator of the level of activity within an industry and may reflect a higher level of internal coordination and organization which is conducive to the management of innovation and thus, to technological innovation. As such, the implementation of the state's policy on environmental regulation will intensify the game of information between managers and enterprises, resulting in increased management costs for corporate operations, thereby stimulating internal technological innovation.

\subsection{Robustness Test}

Efficiency often comes at the cost of robustness. The 3SLS method is more effective than other methods though lacks robustness. Therefore, this paper revisits the environmental regulation to identify variables, which are used to test for robustness using the hypothetical model to examine 35 samples of industrial enterprises above a designated size.

Another agent variable, associated with the level environmental regulation (ERS0), is obtained by selecting the waste water, waste gas, general solid waste emissions, and industrial output values for various industries. The volume of effluent levy discharged per unit of industry is then calculated, and linearly normalized, weighted, and averaged to obtain the indicators for each industry in each period, the total of which amounts to $E R S_{0}$.

The specific processing steps are outlined as follows (Jiang et al., 2013): First, the emission of pollutants per unit of the industry is linearly standardized.

$$
U E_{i j}^{s}=\left[U E_{i j}-\min \left(U E_{j}\right)\right] /\left[\max \left(U E_{j}\right)-\min \left(U E_{j}\right)\right]
$$

Among them, $U E_{i j}$ denotes the pollution emission per unit of production value of $j$ pollutants in the industry $i$. Max $\left(U E_{j}\right)$ and min $\left(U E_{j}\right)$ represent the maximum and minimum values of the pollution emission of $j$ pollutants per unit of production value 
for all industries.

Second, the weight coefficient $\left(W_{j}\right)$ is calculated for each pollutant. As there is a large difference in the units of waste water, waste gas, and general solid waste discharged among the industries, empowerment can provide a better indication of such differences with respect to the various pollutants.

$$
W_{j}=\frac{E_{i j}}{\sum_{i=1}^{m} E_{i j}} / \frac{Y_{i}}{\sum_{i=1}^{m} Y_{i}}=\frac{\sum_{i=1}^{m} Y_{i}}{\sum_{i=1}^{m} E_{i j}} \times \frac{E_{i j}}{Y_{i}}=\frac{E_{i j}}{Y_{i}} / \frac{\sum_{i=1}^{m} E_{i j}}{\sum_{i=1}^{m} Y_{i}}=U E_{i j} / \overline{U E_{i j}}
$$

Among them, $U E_{i j}$ denotes the pollution emission of $j$ pollutants in industry $i . \frac{E_{i j}}{\sum_{i=1}^{m} E_{i j}}$ expresses the proportion of polluting emissions of $j$ pollutants in the industry $i$ for all industries. $Y_{i}$ denotes the industrial output value for industry $i . \frac{Y_{i}}{\sum_{i=1}^{m} Y_{i}}$ expresses that the industrial output of the industry $i$ accounts for the proportion for all industrial sectors. $\overline{U E_{i j}}$ denotes the industry's average level of emissions per unit of production of $j$ pollutants.

Third, the overall level of environmental regulation is calculated by standardizing and empowering the three pollutant indicators.

$$
E R S_{0}=\sum_{i=1}^{p} S_{i}=\sum_{i=1}^{p} \frac{1}{n} \sum_{j=1}^{n} W_{j} \cdot U E_{i j}^{s}
$$

In this study, $E R S_{0}$ is used to replace $E R S$, the logarithm to be included in the equation, and the complete data sample were analyzed using regression. Following 3SLS regression, all explanatory variables are shown to be significant at the $10 \%$ significance level and show that the estimated simultaneous system largely concurs with the existing interpretation i.e., that the level of both environmental regulation and 
816 management costs exerts a significant positive impact on R\&D funding, and that 817 technological innovation is conducive to attracting foreign capital from the 818 Table5results. Furthermore, the results show that the increase in industry profits will 819 attract domestic capital and cause a significant crowding-out effect with respect to 820 foreign capital.

821 Table 5 Results from the Robustness Test for all Samples comprising 35 Industrial Enterprises above a Designated Size

\begin{tabular}{|c|c|c|c|c|}
\hline \multirow{2}{*}{ Variables } & \multicolumn{2}{|c|}{ LnR\&D } & \multicolumn{2}{|c|}{ LnFDI } \\
\hline & OLS & $3 \mathrm{SLS}$ & OLS & 3 SLS \\
\hline LnFDI & $\begin{array}{c}0.161^{* * *} \\
(6.64)\end{array}$ & $\begin{array}{c}0.167^{* * *} \\
(6.25)\end{array}$ & & \\
\hline LnFDI(-1) & & & $\begin{array}{c}0.976^{* * *} \\
(66.32)\end{array}$ & $\begin{array}{l}0.961^{* * *} \\
(51.42)\end{array}$ \\
\hline LnR\&D & & & $\begin{array}{l}0.035 \\
(1.49)\end{array}$ & $\begin{array}{l}0.733^{*} \\
(1.85)\end{array}$ \\
\hline LnPRO & & & $\begin{array}{c}-0.626^{* *} \\
(-2.02)\end{array}$ & $\begin{array}{c}-0.096^{* *} \\
(-2.14)\end{array}$ \\
\hline LnERS $_{0}$ & $\begin{array}{c}0.975^{* *} \\
(2.06)\end{array}$ & $\begin{array}{l}1.108^{* *} \\
(1.97)\end{array}$ & & \\
\hline LnMC & $\begin{array}{c}1.436^{* * *} \\
(33.60)\end{array}$ & $\begin{array}{l}1.433^{* * *} \\
(30.83)\end{array}$ & & \\
\hline $\mathrm{C}$ & $\begin{array}{c}-9.070^{* * *} \\
(-5.86)\end{array}$ & $\begin{array}{c}-9.492^{* * *} \\
(-5.28)\end{array}$ & $\begin{array}{c}0.481^{* * *} \\
(2.85)\end{array}$ & $\begin{array}{c}0.641^{\text {*** }} \\
(2.77)\end{array}$ \\
\hline $\begin{array}{c}\text { Observation } \\
\text { Groups }\end{array}$ & 350 & 313 & 313 & 313 \\
\hline $\mathrm{R}^{2}$ & 0.854 & 0.849 & 0.962 & 0.962 \\
\hline Adjusted $\mathrm{R}^{2}$ & 0.853 & & 0.962 & \\
\hline
\end{tabular}


Note: ${ }^{* * *}$ indicates significant at the $1 \%$ level, ${ }^{* *}$ indicates significant at the $5 \%$ level, ${ }^{*}$ indicates significant at $10 \%$ level; data model brackets correspond to t-statistics (OLS) and z-statistics for each explanatory variable (3SLS). The data in the table were compiled in accordance with the Stata 12.0 SE software output.

From Table 5, it can be seen that the variables in the simultaneous equation system are exactly the same as those in Table 2, which shows that the role of the new agent variable is consistent with the previous full sample analysis, and the coefficient value is larger here. This shows that the impact of the aforementioned analytical environmental regulations on the selection of firms within China's FDI industrial sector has a certain degree of soundness and rationality.

\section{Conclusion and policy implications}

By adopting a framework based on an extension of principal-agent Game Theory, this study develops a hypothesis with respect to three behavioral entities. Companies, managers, and regulators have constructed a dynamic simultaneous equation system in which environmental regulation and management costs affect technological innovation by exerting an influence on the way in which industrial sectors are selected for foreign capital investment. This study uses the 3SLS method to conduct an empirical analysis. The findings of the research reveal that environmental regulation and management costs promote technological innovation and prove conducive to the process of attracting FDI in order to develop the industry. At the same time, FDI can, in turn, promote technological advancement, and there is a clear positive interaction between technological innovation and foreign capital. Therefore, the results suggest that the introduction of environmental regulation and the resultant increase in management costs can, in fact, enhance the internal coordination of the company. The implementation of environmental regulation obliges managers and companies to review their game strategies, and increasing management costs can reflect the degree of internal coordination in the organization. In accordance with the regulation game for management costs, such costs will promote an enterprise's technological 
851 innovation to overcome the organizational inertia. Furthermore, the FDI spill-over 852 effect arising from the increase in $R \& D$ funding is greater than the loss in profit as a 853 result of the management costs. This result is further confirmed by considering the 854 way in which environmental regulation and the resultant introduction of industry 855 management costs has served to promote the introduction of FDI. The empirical 856 analysis shows that the industry's total profit has a significant negative impact on 857 industry selection with respect to foreign capital, and reveals that domestic capital 858 crowds out foreign capital. When foreign investors select industries for investment, 859 they view technological innovation as an important indicator in evaluating an 860 industry's investment potential. The analysis of the measurement results for the R\&D 861 equations shows that environmental regulation and the management costs incurred by the industry have a significant impact on technological advancement and suggest that environmental regulation has promoted the inflow of FDI. However, the analysis of the FDI measurement equations reveal that the negative impact of industry profits on foreign capital is greater than the effect generated from the association between the industry's R\&D and ability to attract foreign capital. Due to the way in which capital 867 chases high profits, domestic capital has a crowding-out effect on foreign capital. However, this crowding-out effect did not reduce the inflow of FDI. As a result of 869 having formulated the environmental regulations, the Chinese government is biased towards the introduction of technology capital with respect to the process of attracting 871 foreign investment, which has been verified in the sub-industry measurement model. 872 Mostly attracting FDI flow into the high-technology industry, and the policy of 873 borrowing chicken to lay eggs is effective. With regard to the period analysis, the first 874 phase (2005-2008) shows that environmental regulation had a significant positive 875 impact on technological innovation, while the interaction effect between technological 876 innovation and foreign capital did not prove significant. The result only shows that the 877 inflow of foreign capital promotes technological innovation within the Chinese 878 industry, indicating that, at this stage, Chinese industrial innovation is driven by 879 external capital, and that foreign capital is directed towards absorbing the Chinese 
market share. In the second phase (2009-2014), environmental regulation and industry management costs promote innovation, and the relationship between innovation and FDI is obviously significant. This result indicates that environmental regulation has promoted the introduction of FDI. The empirical results show that the increasing industry profits of Chinese industrial enterprises began to squeeze out foreign capital to a certain extent .This shows that environmental regulation and management costs lead to a bias in the selection of FDI inflows, such that FDI flows into high-tech industrial enterprises. Once again, the market-for-technical policy has an effect.

In the empirical analysis of sub-industries, an increase in the level of environmental regulation will improve the industry's R\&D funding for technological innovation, which is an important conclusion outlined in the Porter hypothesis. However, the article further explains that the management costs of the industry will oblige managers and enterprises to 're-game' in the environmental regulation game. In this way, environmental regulation can further promote FDI inflows through technological innovation. Therefore, the analysis of the empirical results shows that both the raw materials industry and the general manufacturing industry in the Chinese industrial enterprises sector are supported by Porter's hypothesis in practice, while high-tech industries in opposition to it. The logic underpinning this finding may be understood with reference to way in which Porter's hypothesis is not supported when a weak level of environmental regulation or effluent levy is in force. The internal organization and coordination of enterprises will become more active as a result of the increasing of management costs, which is conducive to organizational innovation and to the provision of a soft environment for technological innovation to attract the flow of FDI. This finding is verified for resource-based industries, raw materials industries, general manufacturing industries, and high-tech industries. Therefore, as a result of the aggregated effects of environmental regulation and management costs, the inflow of Chinese FDI is more biased toward high-tech industries. 
Declarations

910

\section{Ethical Approval and Consent to Participate}

912

913

Not applicable.

914

915

\section{Consent for Publication}

916

917

Not applicable.

918

919

\section{Competing Interest}

920

921

The authors declare that they have no competing interests.

922

923

Funding Acknowledgment Statement:

924

925 Not applicable.

926

927

\section{Authors Contribution}

928

929 All authors made significant contributions to the study conception and design. Data 930 collection and methodology were performed by D.B and L.C.L, S.F did formal 931 analysis and software. D.B wrote the original draft. Review and editing were 932 performed by S.F and Z.A.B.

933

934

\section{Conflict of Interest}

935 
All authors declare that there is no conflict of interest.

\section{Availability of Data}

Data will be available upon request.

\section{References}

Ambec S, Barla P(2002)A theoretical foundation of the Porter hypothesis. Economics Letters. 3(75): 355-360.

Antweiler ,W ., B ,Copeland and S . Taylor (2001)Is Free Trade Good for the environment?American Economic review 91(4):877-908.

Bassem K . Anis O. ,Anissa C(2014)Environmental Regulations ,Trade and Foreign Direct Investment. Evidence from Gravity Equations, Working paper .

Brander J A, Taylor M S(1997)International Trade between Consumer and Conservationist Countries. Resource and Energy Economics. 19(4): 267-297.

Cai X,Lu Y, Wu M, et al (2016)Does Environmental Regulation Drive Away Inbound Foreign Direct Investment? Evidence from a Quasi-Natural Experiment in China.Journal of Development Economic .123:73-85.

Cole M A, Elliot R J R(2005)FDI and the Capital Intensity of "Dirty" Sectors: A Missing Piece of the Pollution Haven Puzzle. Review of Development Economics. 4(9): 530-548.

Cole M A, Elliott R J R, Wu S(2008)Industrial activity and the environment in China: An industry-level analysis. China Economic Review. 19(3): 393-408.

Cheng Qiang(2016)Advanced Econometrics and stata Applications.Higher Education Press in BeiJing.

Chung S(2014)Environmental Regulation and Foreign Direct Investment: Evidence from South Korea. Journal of Development Economics 108(3):222-236.

Dean, J. M. , M. E Lovely and H. Wang(2005)“Are Foreign Investors attracted to Weak Environmental Regulations”, World Bank Policy Research Working Paper.

Dean J M, Lovely M E, Hua W(2009)Are Foreign Investors Attracted to Weak Environmental Regulations Evaluating the Evidence From China?. Journal of Development Economics. 90: 1-47.

Eskeland G. and A. Harrison(2003)Moving to Greener Pastures? Multinationals and the Pollution Haven Hypothesis . Journal of Development Economics.70(1):1-23.

Garofalo G A, Malhotra D M(1995)Effect of Environmental Regulations on 
State-Level Manufacturing Capital Formation. Journal of Regional Science. 2(35): 201-216.

He Jie(2006)Pollution haven hypothesis and environmental impacts of foreign direct investment: The case of industrial emission of sulfur dioxide $\left(\mathrm{SO}_{2}\right)$ in Chinese provinces. Ecological Economics. 60(1): 228-245.

Ilhan Ozturk \& Ali Acaravcı (2010), "FDI, Trade And Growth In Turkey: Evidence From ARDL Bounds Testing Approach”, Argumenta Oeconomica, 25(2), 95-115.

Ilhan Ozturk (2015). Measuring the impact of energy consumption and air quality indicators on climate change: Evidence from the panel of UNFCC classified countries. Environmental Science and Pollution Research, 22(20), 15459-15468.

Ilhan Ozturk (2017). The Dynamic Relationship between Agricultural Sustainability and Food-Energy-Water Poverty in a Panel of Selected Sub-Saharan African Countries. Energy Policy, 107, 289-299.

Jiang FUxin, Wang Zhujun ,Bai Junhong(2013)The Dual Effect of Environmental Regulations' Impact on Innovation_ An Empirical Study Based on Dynamic Panel Data of Jiangsu Manufacturing.Industrial Economy Journal. (7): 44-55 in Chinese.

Jiang $\operatorname{Ke}(2010)$ The Chinese Environmental Regulation influence Foreign Direct Investment.Wu Han ,Huazhong University of Science and Technology in Chinese.

Keller W ,.Levinson A (2002)Environmental Regulation $\mathrm{s}$ and FDI to US States .Review of Economics \&Statistics .84(4):691-703.

List ,J .A.and C.Y.Co(2000)The Effects of Environmental Regulations on Foreign Direct Investment .Journal of Environmental Economics and Management .40:1-20.

Levinson A(1996)Environmental regulations and manufacturers' location choices: Evidence from the Census of Manufactures. Journal of Public Economics. .62(2): 5-29.

List J A, Mchone W, Lee J, et al(1999)Effects of Air Quality Regulation on Manufacturing Births: Evidence from a Panel of Countries in New York State. Working Paper AREC: University of Maryland.

Liu Zhizhong, Chen Guo(2009)Environmental Regulations and Location Distribution of Foreign Direct Investment -Empirical Study Based on Urban Panel Data..International trade issues Journal .(3): 61-69 in Chinese.

Ma Fuping ,Guo Xiaochuan,Cha Na(2011)The Study on the Impact of Environmental Regulation on Technological Innovation Performance :Empirical Test Based on Resource-based Enterprises..Science of Science and Management of S\&T Journal .(8): 
87-92 in Chinese.

Mcconnell V, Schwab R M(1990)The Impact of Environmental Regulation on Industry Location Decisions: The Motor Vehicle Industry . Land Economics. 66(1): 67-81.

Qi Jianhong Ju Lei(2007)An Empirical Analysis on Environment en tal Regulation and FDI Location Co-integration and Granger Test Based on Chines data of 1985-2004..Finance and Trade Economic Journal .(3): 10-31 in Chinese.

Rock M T(2002)Pathways to industrial environmental improvement in the East Asian newly industrializing economies. Business Strategy and the Environment. 11(2): 90-102.

Shen Neng,Liu Fengchao(2012)Can Intensive Environmental Regulation Promote Technological Innovation?Porter Hypothesis Re-examined.Chinese Soft Science Journal.(4): 49-59 .

Shi Beibei,Feng Chen,Zhang Yan, Yang Fei(2017) Increasing Marginal Effect of Environmental Regulation Dividend .Chinese Industry Economic Journal.(12):40-58.

Shi Qing . Foreign Direct Investment ,Environmental Regulation and Environmental Pollution - From The Perspective of Government Honest Degree.Finance \&Trade Economics in China,2013(1): 93-103.

Walter I, Ugelow J(1979)Environmental Policies in Developing Countries. Ambio. (8): 102-109.

Wang Guoyin, WangDong(2011)Porter Hypothesis ,Environmental Regulation and Enterprises' Technological Innovation_-The Comparative Analysis Between Central China and Eastern China.Chinese Soft Science Journal.(1): 100-112 in Chinese.

Wang Ran, Yan Bo, Deng Weigen(2010)The Impact of FDI on the Independent Innovation Capability of Chinese Indigenous Industries - From the Perspective of Industrial Linkages.Chinese Industrial Economy Journal .(11): 16-25 in Chinese.

Wheeel ,D(2001)Race to the bottom ? Foreign Investment and Air Pollution in Developing Countries. Journal of Environment and Development.10:225-245.

Wu Lei , Li Guanghao , Li Xiaofan(2010)Chinese Environmental Regulation and Industry Entry of FDI Enterprises.Chinese population,Resources and Environment Journal.(08): 92-98 in Chinese.

Xing ,Y .and C.D .Kolstad (2002)Do Lax Environmental Regulations Attract Foreign Investment .Environmental and Resources Economics .21.:1-22. 
1037 Xiong Ying ,Xu Xiang(2007)Environmental Regulation Influence Chinese 1038 FDI-Empirical Study on the panel data Model.Economic Review Journal (2): $1039 \quad$ 122-124 in Chinese.

1040 Yu Donghua ,Hu Yanan(2016)Does Tightening Environmental Regulation Impede 1041 Technological Innovation Upgrading of Manufacturing Industries in China? _ An 1042 Empirical Re-Examination on Porter Hypothesis.Journal of Industrial Economic 1043 Research .(2): 11-20 in Chinese.

1044 Zarsky L(1999)Untangling the Evidence about Foreign Direct Investment, in Foreign 1045 Direct Investment and the Environment . London: OECD Press.47-74.

1046 Zeng Xiangang(2010)Environmental Regulation ,Foreign Direct Investment And 1047 "Pollution Haven" Hypothesis.Economic Theory and Economic Management 1048 Journal .(11): 65-71 in Chinese.

1049 Zhang Cheng , Zhu Qianlong ,Yu Tongshen(2011)Relationship between 1050 Environmental Pollution and Economic Growth.Statistical Research Journal . 28(1): $1051 \quad 59-67$ in Chinese.

1052 Zhang Cheng ,Lu Yang ,Guo Lu .and Yu Tongshen(2011)The intensity of 1053 Environmental Regulation and Technological Progress of Production.Economic 1054 Research Journal .(2): 113-124 in Chinese.

1055 Zhou Changfu, Du Yuwei, Peng Anping(2016)Environmental Regulations Affect the 1056 Location Selection of FDI?: Empirical Study Based on Cost Perspective.World 1057 Economy studies Journal.(1): 110-120 in Chinese. 